\title{
Effect of Wetness Duration and Incubation Temperature on Development of Ascosporic Infections by Sclerotinia sclerotiorum
}

\author{
F. Shahoveisi and L. E. del Río Mendoza, ${ }^{\dagger}$ \\ Department of Plant Pathology, North Dakota State University, Fargo, ND 58108
}

\begin{abstract}
The impact of wetness duration and incubation temperatures on Sclerotinia sclerotiorum ascospore germination and ascosporic infection efficiency were evaluated. Ascospore germination was optimal when incubated in continuous moisture (free water) at $21^{\circ} \mathrm{C}$. Significantly lower germination was observed at 10 or $30^{\circ} \mathrm{C}$. Interrupting ascospore wet incubation was detrimental for germination. In infection efficiency studies, dry bean and canola flowers were inoculated with dry ascospores and placed on leaves of dry bean and canola plants, respectively. Dry

dry periods. Interrupting wet incubation delayed symptom appearance and hindered development of the epidemics on both plant types. Logistic regression models estimated at 50\% the probability of disease development on dry bean and canola plants when 68 and $48 \mathrm{~h}$ of wet incubation at $20^{\circ} \mathrm{C}$ accumulated in a period of 6 days, respectively. The canola model was validated using data from field trials. Results of these studies will contribute to develop more accurate warning models for diseases caused by $S$. sclerotiorum.
\end{abstract} bean plants were incubated for $196 \mathrm{~h}$ at 18 to $20^{\circ} \mathrm{C}$ in alternating 8 to $16 \mathrm{~h}$ wet/12 to $24 \mathrm{~h}$ dry periods. Canola plants were incubated for $240 \mathrm{~h}$ at $10,15,20,25$, or $30^{\circ} \mathrm{C}$ in alternating 6 to $18 \mathrm{~h}$ wet/ 18 to $6 \mathrm{~h}$
Keywords: fungi, epidemiology, disease warning systems, field crops, oilseeds and legumes
The fungus Sclerotinia sclerotiorum (Lib.) de Bary is endemic to the state of North Dakota where it causes economically significant losses in canola, dry bean, and sunflower (del Río et al. 2007). In addition to these crops, however, S. sclerotiorum can attack more than 400 other plant species including some currently under evaluation as alternative crops for North Dakota (Chapara et al. 2018; del Río et al. 2005).

Most diseases caused by S. sclerotiorum are initiated by ascospores (Abawi and Grogan 1975), although on sunflowers, myceliogenic germination of sclerotia could also result in Sclerotinia wilt (Foley et al. 2016). Earlier studies indicated that "successful inoculation with ascospores required free moisture for approximately 48 to $72 \mathrm{~h}$, at optimum temperature of 20 to $25^{\circ} \mathrm{C}$, before signs of infection were evident" (Abawi and Grogan 1975); later, observations by other researchers widened that range to 40 to $112 \mathrm{~h}$, at temperatures of 12 to $24^{\circ} \mathrm{C}$ (Boland and Hall 1988; Young et al. 2004). Under field conditions, however, continuously wet periods of such lengths are the exception rather than the norm; instead, periods of high humidity, usually at night and dawn, are alternated with periods of low humidity during the day. The impact of alternating wet and dry periods on disease development varies depending not only on the length and timing of dry period occurrence but also on the pathogen involved (Magarey et al. 2005), with S. sclerotiorum being very tolerant to desiccation once established in floral tissues (Harikrishnan and del Río 2006); however, very little is known about the moisture requirements and the impact of interrupted wetness on ascospore germination and the initial stages of disease development. Incubation temperature is another important factor affecting the establishment and development of $S$. sclerotiorum in the host. The lower and upper temperature limits for growth and development of this fungus are 7 to

${ }^{\dagger}$ Corresponding author: L. E. del Río Mendoza;

luis.delriomendoza@ndsu.edu

Funding: This research was funded by the USDA-ARS National Sclerotinia Initiative through Specific Cooperative Agreement No. 58-5442-5-289, and USDA-NIFA Hatch Program Award ND02349.

The author(s) declare no conflict of interest.

Accepted for publication 3 January 2020.

(C) 2020 The American Phytopathological Society $30^{\circ} \mathrm{C}$, with an optimum of 20 to $25^{\circ} \mathrm{C}$ (Abawi and Grogan 1975 ; Harikrishnan and del Río 2006; Uloth et al. 2015). However, its effect in combination with wetness periods has not been thoroughly investigated. We conducted studies to address the effect of wetness periods and incubation temperatures on ascospore germination and incidence of S. sclerotiorum on dry bean (Phaseolus vulgaris) and canola (Brassica napus).

\section{Materials and Methods}

All experiments were conducted using S. sclerotiorum ascospores produced under laboratory conditions. Briefly, sclerotia produced in cornmeal-sand medium were conditioned for carpogenic germination by three successive cycles of $24 \mathrm{~h}$ freeze at $-20^{\circ} \mathrm{C}$ then $24 \mathrm{~h}$ thaw at $21^{\circ} \mathrm{C}$ (Harikrishnan and del Río 2006). Conditioned sclerotia were stored at $0^{\circ} \mathrm{C}$ until used. To produce ascospores, conditioned sclerotia were buried in sterile white sand contained in $9 \mathrm{~cm}$ diameter polystyrene Petri dishes. Sand was saturated with sterile distilled water and the sclerotia incubated at $21^{\circ} \mathrm{C}$ and $12 \mathrm{~h} \mathrm{light/dark} \mathrm{for} 5$ weeks. Apothecia were usually formed within 30 days.

Ascospore germination study. Apothecia used for ascospore germination studies discharged the spores on the dish lids. Lids were replaced daily, and ascospores-laden lids were stored in dry conditions at $4^{\circ} \mathrm{C}$ until used. At the time of use, the ascospores were washed off the lids with sterile distilled water and collected in vials. Ascospore concentrations were estimated using a hemacytometer and adjusted to $5 \times 10^{4}$ ascospores $\mathrm{ml}^{-1}$. Three studies were conducted to characterize the ascospore germination process. The first study characterized germination of ascospores in free water at $21^{\circ} \mathrm{C}$. Various incubation periods ranging from 2 to $24 \mathrm{~h}$, at 2-h intervals, were evaluated. Experiments for this study were conducted twice using a completely randomized design (CRD) with three replications each time. A $20 \mu \mathrm{l}$ aliquot of a $5 \times 10^{4}$ ascospore $\mathrm{ml}^{-1}$ suspension of spores from isolate WM030, collected from a soybean field in Nebraska, was deposited in 36 individual cover glass slides and the slides were placed on glass rods in a clear plastic crisper. A film of water was deposited at the bottom of the crisper, under the slides, and the crisper was sealed to prevent the droplets from drying out. Spores were incubated at $21^{\circ} \mathrm{C}$ with $12 \mathrm{~h} \mathrm{light/dark}$. At the end of each incubation period, three slides were retrieved and 50 spores in each slide were examined for germination using a compound microscope (Carl Zeiss, Axiostar Plus). An ascospore was considered germinated when the length of its germ tube was equal or greater than one-half the diameter of the spore. 
The second study evaluated the impact of interrupting the wet incubation of ascospores for a period of 0 to $16 \mathrm{~h}$ on their germination. The treatments for this study were arranged factorially in a CRD. Each of the 16 treatments was replicated three times and the entire experiment repeated once. Here, $20 \mu \mathrm{l}$ of an ascospore suspension were deposited on five slides per treatment and replication. The ascospores were initially suspended in sterile distilled water and incubated for 2, 4, 6, or 8 consecutive hours. At the end of each period, one slide was used to establish a germination baseline, while the other four were moved to a dry crisper where the aliquots disappeared from the slide's surface within $30 \mathrm{~min}$. The slides were incubated in the dry crisper for $4,8,12$, or $16 \mathrm{~h}$ at $21^{\circ} \mathrm{C}$ with relative humidity at $35 \%$. After the dry incubation, the ascospores in all treatments were rewetted by carefully placing an aliquot of distilled water on them and incubated for an additional $24 \mathrm{~h}$ as described. Spore germination and length of germ tube were quantified at the end of the second incubation period as described. Mean ascospore germination prior to each drying period was used as a reference point; if germination after the drying period was numerically smaller than the reference point, the reference point was used as the germination value; if it was greater, then the actual value was used. The length of germ tubes was measured as described and contrasted with the length of germ tubes of the reference slide for each treatment.

The third study was conducted to evaluate the effect of different incubation temperatures on ascospore germination of S. sclerotiorum isolates WM031 from Nebraska and WM061 and WM192 from North Dakota. These isolates had been collected from soybean, lupins, and canola, respectively. The study was conducted twice in a CRD with four replications for each temperature. Forty microliter aliquots of spore suspensions were placed on glass cover slides and the covers were placed on wet paper towel in Petri dishes. The dishes were closed and incubated at 10,21 , and $30^{\circ} \mathrm{C}$ for $8 \mathrm{~h}$. After this period, the number of germinated spores and length of the germ tubes were measured using 50 spores per sample. Spore germination for isolates incubated at $30^{\circ} \mathrm{C}$ were also assessed after $48 \mathrm{~h}$. The latter were made to verify recent observations suggesting ascospores were not able to germinate at $30^{\circ} \mathrm{C}$ (Clarkson et al. 2014). Isolates within each temperature were compared based on mean of spore germination.

Infection efficiency studies. Flowers used in these studies were inoculated with dry ascospores. Briefly, flowers were placed in the top two levels of a six-stage Andersen spore sampler (Andersen 1958). A funnel, attached to the intake orifice of the sampler, was placed on top of a dish containing mature apothecia and the sampler activated for approximately $30 \mathrm{~s}$. A small number of inoculated flowers were incubated for $72 \mathrm{~h}$ at $21^{\circ} \mathrm{C}$ in Petri dishes containing wet paper towels. After incubation, flowers with visible mycelial growth were counted and mycelia were transferred to dishes containing potato dextrose agar (PDA) or blue medium (Steadman et al. 1994). Presence of sclerotia on PDA and development of yellow halo on blue medium were used as confirmation that they belonged to $S$. sclerotiorum.

Dry bean. Dry bean flowers from cv. Maverick were collected from greenhouse plants and kept in storage at $4^{\circ} \mathrm{C}$ for $>12 \mathrm{~h}$ before use to preserve their freshness. These flowers were deposited in single layers on dish bottoms and the dishes placed in the top two stages of an Andersen spore sampler. The sampler was attached to a funnel and inverted above a dish containing mature apothecia from isolate WM030. The sampler was operated for $30 \mathrm{~s}$ and after that, groups of five inoculated flowers were deposited on the upper surface of primary leaves of individual dry bean seedlings, cv. Maverick, at the V-1 stage (one fully expanded trifoliate). These plants were subjected to 10 combinations of alternating wet and dry conditions (Table 1). Each treatment was replicated four to five times in a CRD with a single plant in each replication. The study was conducted four times. During the wet incubation, plants were kept in moist chambers at $20^{\circ} \mathrm{C}$. Cool-mist humidifiers (Vicks, V3700) operating for $3 \mathrm{~min}$ at 20-min intervals provided a saturated atmosphere and prevented leaf surfaces from drying. At the end of each wet period, plants were moved into a room set at $18^{\circ} \mathrm{C}$ with relative humidity at $30 \pm 5 \%$.
Under these conditions, visible water disappeared from the leaves in approximately $20 \mathrm{~min}$. At the time when plants were returned to moist chambers, leaves were sprayed again with water until runoff. Disease incidence, estimated as the percentage of flowers that produced visible lesions on leaf tissues, was recorded every time plants were returned to moist conditions.

Canola. Canola flowers from cv. Westar, collected on the day of inoculation, were inoculated with dry ascospores of isolate WM031 as described. Groups of 10 inoculated flowers were deposited on leaves of single canola plants, cv. Westar, at the six-leaf growth stage. These plants were subjected to four combinations of alternating wet and dry conditions (Table 2), while being incubated at $10,15,20$, or $30^{\circ} \mathrm{C}$ for 10 days. For each temperature, treatments were evaluated using a randomized complete block design with three replications. A plastic bag containing single plants from each treatment was considered a replication. The bags were kept closed to keep wet incubation conditions constant and were opened momentarily only when a treatment was either ending or starting wet incubation conditions. For treatments starting dry incubation, plants were removed from the bags but kept in the growth chamber. Visible moisture on leaves of plants outside the bags disappeared within 20 to $90 \mathrm{~min}$. Plants starting a new wet incubation cycle were sprayed with distilled water until runoff and put back in the corresponding plastic bag. The number of foliar lesions caused by S. sclerotiorum on each plant was recorded daily and expressed as a percentage.

Data analyses and model development. All data analyses were conducted using SAS software (version 9.4; SAS Institute, Cary, NC). For the first study on ascospore germination, the means and their standard errors were calculated and plotted to visualize the effect of time on germination. For the second study on ascospore germination, the means and standard errors of the increments in germination were plotted to visualize the interaction between duration of wet incubation and length of drying periods. For the third study on ascospore germination and for the studies on infection efficiency, Levene's test for homogeneity of variances $(P \leq 0.05)$ was conducted to determine whether trials within each study could be combined for analysis. When permitted, combined analyses of variance were conducted using the general linear model procedure considering trials, and the interaction between trials with treatments as random effects. Treatments (e.g., isolates, incubation temperatures, and wetness durations) were considered as fixed effects. F-tests for treatments were conducted using their interactions with trials as denominators and Fischer's protected least significant difference (LSD) tests at $P=0.05$ were conducted to discriminate between treatment means using proper sources of error. For infection efficiency studies on dry bean and canola, these tests were conducted to compare the length of the latent periods, defined as the time between inoculation and the expression of first symptoms, and the highest

Table 1. Impact of interrupted moisture conditions on length of latent period, and disease incidence caused by Sclerotinia sclerotiorum ascosporic infection on dry bean $144 \mathrm{~h}$ post inoculation

\begin{tabular}{|c|c|c|c|c|}
\hline \multicolumn{3}{|c|}{ Incubation conditions (h) ${ }^{\mathbf{a}}$} & \multirow{3}{*}{$\begin{array}{l}\text { Latent period } \\
\text { (h) }\end{array}$} & \multirow{3}{*}{$\begin{array}{c}\text { Incidence } \\
(\%)\end{array}$} \\
\hline \multicolumn{2}{|c|}{ Daily } & \multirow{2}{*}{$\begin{array}{c}\text { Cumulative } \\
\text { wet }\end{array}$} & & \\
\hline Wet & Dry & & & \\
\hline 8 & 12 & 78 & 157 & 64 \\
\hline 8 & 18 & 60 & 172 & 46 \\
\hline 8 & 24 & 49 & 189 & 17 \\
\hline 12 & 12 & 98 & 149 & 57 \\
\hline 12 & 18 & 78 & 170 & 50 \\
\hline 12 & 24 & 65 & 177 & 37 \\
\hline 16 & 12 & 112 & 107 & 79 \\
\hline 16 & 18 & 92 & 121 & 86 \\
\hline 16 & 24 & 78 & 153 & 55 \\
\hline 24 & 0 & 196 & 99 & 78 \\
\hline \multicolumn{2}{|c|}{ 1.s.d. $(P=0.05)$} & & 19 & 20 \\
\hline
\end{tabular}

${ }^{a}$ Each treatment mean represents the average of 17 replications. 
amount of disease incidence that was calculated $144 \mathrm{~h}$ after inoculation.

The association between duration of the wet period and disease incidence was modeled using logistic regression analysis (SAS version 9.4). Logistic regression provides estimates of the probability that a foliar lesion will be produced from ascospore-inoculated flowers. For the analyses, data were classified as either 0 or 1 , depending on whether disease incidence was $\leq 20 \%$ or $>20 \%$, respectively (Harikrishnan and del Río 2008; Rothmann and McLaren 2018). Disease data collection started after 38 and $24 \mathrm{~h}$ of incubation and continued until 196 and $240 \mathrm{~h}$ on dry bean and canola trials, respectively. Models using wetness duration as the predictor were developed for dry bean using disease status data at $72 \mathrm{~h}$ and then at $24 \mathrm{~h}$ increments. A similar approach was used to develop a model for canola with wetness duration, and the linear and quadratic effects of incubation temperatures as predictors. In disease favorable temperatures, data collection was started $24 \mathrm{~h}$ after inoculation.

Models were evaluated following standard procedures that included comparing fitness statistics like Akaike Information Criterion, Schwarz Criterion, and the -2 Log L; their percentage of concordant and discordant pairs, Sommer's D, Gamma, Tau-a, and $c$ statistics; and the Hosmer and Lemeshow test that evaluates the model's predictive capability (Hosmer and Lemeshow 2000). The selected models, one for each crop, were validated on data sets not used for model development. The sensitivity and specificity of these models were calculated as described by Coughlin et al. (1992) and their overall accuracy estimated using the equation:

$$
\begin{aligned}
\text { Accuracy } & =\left(\text { Sensitivity } * \frac{\text { observed controls }}{\text { total observations }}\right) \\
& +\left(\text { Specificity } * \frac{\text { observed cases }}{\text { total observations }}\right) .
\end{aligned}
$$

In addition, the predicted probabilities produced by the dry bean and the canola models for $20^{\circ} \mathrm{C}$ were compared using $95 \%$ confidence intervals estimated as described by Hosmer et al. (2013).

Field validation of canola model. The model developed for canola was validated in field trials conducted at Prosper, Carrington, Langdon, and Hansboro, North Dakota, between the second and third weeks of July 2018. Trials at each location had five replications and six flowers per replication and were conducted three times, except at Carrington where they were conducted twice. Flowers inoculated with dry ascospores of S. sclerotiorum as described, were placed on leaves in the lower third of canola plants growing in commercial fields or research plots and fastened in position using paper clips. Leaves with attached flowers were observed 7 days postinoculation for lesion development. Weather data from stations of the North Dakota Agricultural Weather Network (https://ndawn.ndsu. nodak.edu/) closest to each trial were used to calculate the number of daily hours when leaf moisture was likely to occur. A $2^{\circ} \mathrm{C}$ difference between air temperature and dew point temperature was considered as indicator of dew formation on leaves (Huber and Gillespie 1992; Wang et al. 2019) and was used in lieu of leaf wetness sensors. $\chi^{2}$ test of independence was conducted to evaluate the null hypothesis that observed and predicted values were independent from each other.

\section{Results}

Ascospore germination study. Approximately $10 \%$ of ascospores germinated within $2 \mathrm{~h}$ of incubation and by the fourth hour, more than $60 \%$ of ascospores had already germinated. Maximum germination was reached within $6 \mathrm{~h}$ of incubation (Fig. 1). The length of germ tubes increased linearly with time; the average length after $6 \mathrm{~h}$ of incubation was $8 \mu \mathrm{m} ; 6 \mathrm{~h}$ later it was $12 \mu \mathrm{m}$; and after $24 \mathrm{~h}$ of incubation the average germ tube length was $28 \mu \mathrm{m}$ and the tubes had already started to branch out. Interrupting the incubation period by drying the spores for any length of time prevented germination of additional spores except when the interruption occurred within the first $2 \mathrm{~h}$ of incubation (Fig. 2). Significant differences $(P=0.05)$ in spore germination were observed among isolates when incubated at $21^{\circ} \mathrm{C}$; after $8 \mathrm{~h}$ at this temperature, isolates WM31 and WM61 had mean germinations of $85 \%$ each while WM192 had a mean of $69 \%$. After $24 \mathrm{~h}$ of incubation at $21^{\circ} \mathrm{C}$, profuse hyphal development and branching were observed on all isolates. No observations were made at longer incubation times. Spore germination after $8 \mathrm{~h}$ of incubation at 10 and $30^{\circ} \mathrm{C}$ was $<10 \%$ for all isolates. After $24 \mathrm{~h}$ of incubation at $30^{\circ} \mathrm{C}$, the average germination for isolates WM31, WM61, and WM192 was $13 \%$. No branching was observed at this time and germ tubes were typically no longer than the diameter of the spore. After $48 \mathrm{~h}$ of incubation at $30^{\circ} \mathrm{C}$, significant differences $(P=0.05)$ were observed in germination among isolates; isolates WM61 and WM192 had average germinations of $10 \%$ while isolate WM31 had $35 \%$ germination and an average germ tube length of $7 \mu \mathrm{m}$.

Infection efficiency studies. All inoculated dry bean and canola flowers were colonized by $S$. sclerotiorum when incubated in wet chambers for $72 \mathrm{~h}$.

Dry bean. Foliar lesions developed in all treatments; however, in general, alternating moist and dry incubation conditions prolonged the latent period and contributed to reduce the final amount of disease incidence compared with continuous-moisture incubation (Table 1). The shortest latent period (mean of $99 \mathrm{~h}$ and range of 72 to $128 \mathrm{~h}$ ) was observed on plants incubated under continuous moisture conditions; interrupting this condition extended the latent period by an average of $56 \mathrm{~h}$. Plants incubated under continuous moisture had an average disease incidence of $78 \%$. Alternating $24 \mathrm{~h}$ of dry conditions with 8,12 , or $16 \mathrm{~h}$ of wet incubation resulted in significant $(P=0.05)$ reductions in disease incidence; however, reducing the dry period to $18 \mathrm{~h}$ reduced disease incidence significantly $(P=0.05)$ only if the wet incubation was shorter than $16 \mathrm{~h}$. In general, epidemics produced by treatments that alternated 8 or $12 \mathrm{~h}$ of moist conditions with 12 or $18 \mathrm{~h}$ of dry conditions had statistically similar $(P<0.001)$ latent periods, reached $50 \%$ incidence at similar times, and produced similar amounts of disease incidence after $144 \mathrm{~h}$ of incubation (Table 1).

Table 2. Impact of interrupted wetness period and incubation temperature regimes on length of latent period, and disease incidence caused by Sclerotinia

\begin{tabular}{|c|c|c|c|c|}
\hline \multirow{2}{*}{$\begin{array}{l}\text { Temperature } \\
\left(\mathrm{C}^{\circ}\right)\end{array}$} & \multicolumn{2}{|c|}{ Wetness duration $(h)^{\mathrm{a}}$} & \multirow{2}{*}{$\begin{array}{c}\text { Latent } \\
\text { period }(h)\end{array}$} & \multirow{2}{*}{$\begin{array}{c}\text { Incidence } \\
(\%)\end{array}$} \\
\hline & Daily & Accumulated & & \\
\hline 10 & 6 & 42 & 168 & 3 \\
\hline 10 & 10 & 70 & 168 & 3 \\
\hline 10 & 14 & 98 & 158 & 2 \\
\hline 10 & 18 & 126 & 158 & 9 \\
\hline 15 & 6 & 42 & 156 & 48 \\
\hline 15 & 10 & 70 & 124 & 50 \\
\hline 15 & 14 & 98 & 114 & 64 \\
\hline 15 & 18 & 126 & 114 & 73 \\
\hline 20 & 6 & 42 & 112 & 55 \\
\hline 20 & 10 & 70 & 116 & 55 \\
\hline 20 & 14 & 98 & 110 & 65 \\
\hline 20 & 18 & 126 & 90 & 68 \\
\hline 25 & 6 & 42 & 119 & 80 \\
\hline 25 & 10 & 70 & 100 & 73 \\
\hline 25 & 14 & 98 & 98 & 78 \\
\hline 25 & 18 & 126 & 102 & 79 \\
\hline 30 & 6 & 42 & 88 & 39 \\
\hline 30 & 10 & 70 & 76 & 35 \\
\hline 30 & 14 & 98 & 58 & 33 \\
\hline 30 & 18 & 126 & 46 & 75 \\
\hline \multicolumn{5}{|c|}{ 1.s.d. $(P=0.05)^{\mathrm{b}}$} \\
\hline 10 & & & 6.2 & ns \\
\hline 15 & & & 24 & 28 \\
\hline 20 & & & 18 & 19 \\
\hline 25 & & & 21 & ns \\
\hline 30 & & & ns & 23 \\
\hline
\end{tabular}
sclerotiorum ascosporic infection on canola $144 \mathrm{~h}$ post inoculation

a Each treatment mean represents the average of six replications.

b 1. s.d. $=$ least significant difference calculated at $P=0.05$ for each temperature were rounded to whole numbers; ns = not significant. 
The model that best described the association between moisture and disease development was

$$
P=\frac{1}{1+e^{-(-7.39+0.11 * \text { moist })}}
$$

where: $P=$ probability of disease development, and moist $=$ cumulative number of hours of wet conditions. The model, which was based on $144 \mathrm{~h}$ of incubation and used a probability threshold of $P=0.30$ to classify predictions as cases, had an estimated sensitivity and specificity of $88 \%$ and $86 \%$, respectively (Table 3 ) and was significant at $P<0.0001$. According to this model, the probability of disease development was at 50\% when $68 \mathrm{~h}$ of leaf wetness accumulated in a period of $144 \mathrm{~h}$. Such probability increased to $80 \%$ when the hours of accumulated leaf wetness increased to 81 during the same incubation period. When validated on the independent data set, the model had an accuracy of $85 \%$ with a sensitivity of $83 \%$ and a specificity of $87 \%$ (Table 3 ).

Canola. The disease developed on leaves at all incubation temperatures and wetness duration periods. The latent period ranged from 2 days at $30^{\circ} \mathrm{C}$ and $18 \mathrm{~h}$ of wetness to 7 days at $10^{\circ} \mathrm{C}$ and $6 \mathrm{~h}$ of wetness. At 15,20 , and $25^{\circ} \mathrm{C}$, the latent period ranged between approximately 4 and 6 days and the various evaluated wetness durations did not cause significant differences among them (Table 2). Results of infection efficiency studies showed that $25^{\circ} \mathrm{C}$ is the optimum temperature for disease development with the lowest disease incidences being observed on plants incubated at $10^{\circ} \mathrm{C}$ regardless of wetness duration (Table 2). The model $(P<0.001)$ that best described the association between temperature, wetness periods, and disease development was

$$
P=\frac{1}{1+e^{-\left(-20.62+0.046 * \text { moist }+1.57 * \text { temp }-0.033 * \text { temp }^{2}\right)}}
$$

where: $P=$ probability of disease development, moist $=$ cumulative number of hours of wet conditions in a 144-h period, temp $=$ incubation temperature $\left({ }^{\circ} \mathrm{C}\right)$, and temp ${ }^{2}=$ quadratic effect of temperature.

This model, based on $144 \mathrm{~h}$ of incubation, used a probability threshold of $P=0.38$ instead of the default value of $P=0.50$ (Hosmer and Lemeshow 2000) to classify predictions as cases and had an estimated sensitivity and specificity of $77 \%$ and $74 \%$, respectively (Table 3 ). Incubation temperature heavily influenced the probability

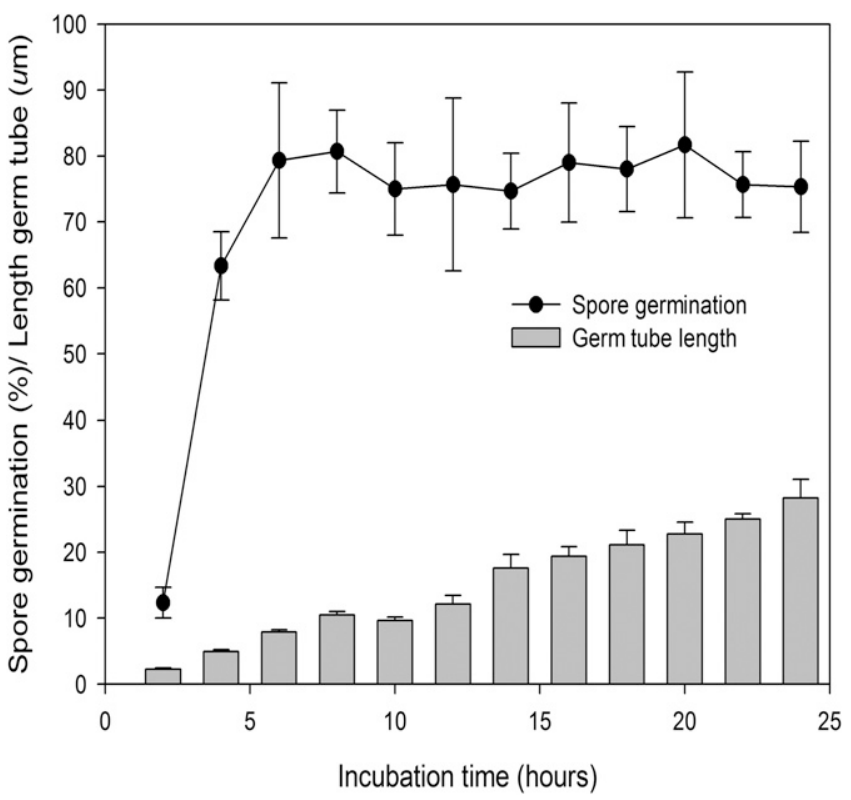

Fig. 1. Germination and length of germ tubes of Sclerotinia sclerotiorum ascospores, incubated at $21^{\circ} \mathrm{C}$ in a film of water, as a function of time. Error bars represent standard error of means. of disease development. As the incubation temperature departed from the optimum, the moisture requirement to have $50 \%$ probability of disease development increased from $36 \mathrm{~h}$ at $25^{\circ} \mathrm{C}$ to $48 \mathrm{~h}$ at $20^{\circ} \mathrm{C}$, $60 \mathrm{~h}$ at $30^{\circ} \mathrm{C}$, and $96 \mathrm{~h}$ at $15^{\circ} \mathrm{C}$ (Fig. 3). When validated on the independent data set, the accuracy of the model was estimated at $73 \%$ with a sensitivity of $79 \%$, and a specificity of $70 \%$ (Table 3 ).

The models developed for dry bean and canola plants suggested the moisture required for disease development on each crop was slightly different. According to the dry bean model, a 50\% probability of disease development on dry bean plants would be reached when $68 \mathrm{~h}$ of wet incubation at $20^{\circ} \mathrm{C}$ accumulated in a period of 6 days (Fig. 4A). The canola model estimated that under the same incubation conditions, a similar probability would be reached on canola plants after $48 \mathrm{~h}$ (Fig. 4B). According to the models, however, the difference in moisture requirements would be progressively smaller as the number of accumulated hours of wet incubation increased. Accumulation of $\geq 70 \mathrm{~h}$ of wetness in a 6-day period produced statistically similar probabilities of disease development for both crops.

Field validation of canola model. The independence test showed that observed and predicted values were not independent from each other and null hypothesis was rejected at $P=0.05$. During field validation, the model predicted with a $77 \%$ accuracy the instances when disease would occur (i.e., sensitivity) and with a $72 \%$ accuracy the instances when diseases would not occur (i.e., specificity). The overall accuracy of the model during validation was $75 \%$ (Table 3 ).

\section{Discussion}

This work characterized the effect of wetness periods and incubation temperatures on ascospore germination and development of foliar lesions by $S$. sclerotiorum on dry bean and canola plants and modeled the relationship between incubation conditions and disease development. Ascospores germinated swiftly in free water but interrupting wet incubation was detrimental for germination. Ascospore germination was highest when incubated at $21^{\circ} \mathrm{C}$ and marginal at 10 or $30^{\circ} \mathrm{C}$. Similarly, lesion development was hampered when wet incubation conditions were interrupted for six or more hours daily. Logistic regression models estimated at $50 \%$ the chance of lesion development on dry bean and canola leaves when the number of cumulative wet incubation hours were at 68 and $48 \mathrm{~h}$ in a period of 6 days, respectively.

Ascospores germinated readily when suspended in water. Approximately $10 \%$ of them did so within $2 \mathrm{~h}$ and by the sixth hour maximum germination, at about $80 \%$, was reached. The ability of $S$. sclerotiorum ascospores to germinate quickly has been documented by other researchers although under different incubation conditions. Garg et al. (2010) indicated most ascospores germinated within $4 \mathrm{~h}$ when incubated at $18^{\circ} \mathrm{C}$ whereas Clarkson et al. (2014) and Young et al. (2004) reported most ascospores germinated within 8 to $10 \mathrm{~h}$ when incubated at temperatures between 15 and $25^{\circ} \mathrm{C}$. While

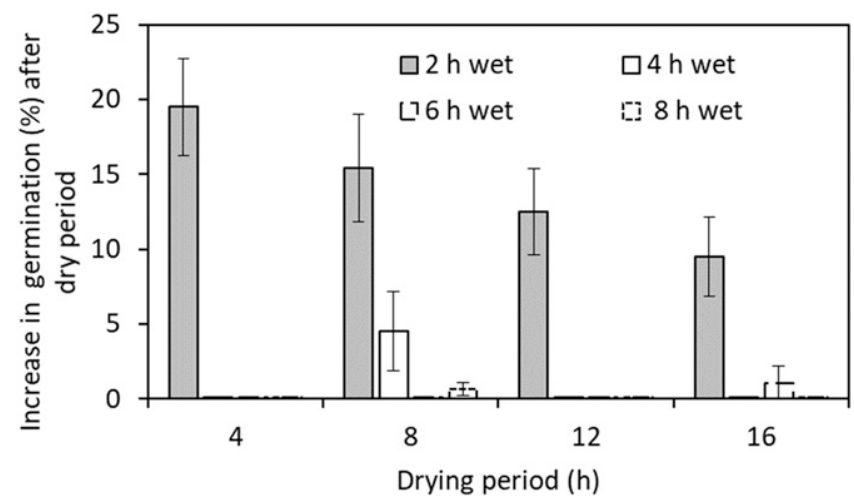

Fig. 2. Effect of interrupted wet incubation on germination of Sclerotinia sclerotiorum ascospores. Ascospores were incubated in wet conditions for 2, 4, 6, or $8 \mathrm{~h}$, then dried for $4,8,12$, or $16 \mathrm{~h}$, and incubated in wet conditions for another $24 \mathrm{~h}$. Error bars represent standard error of means. 
incubation at 10 or $30^{\circ} \mathrm{C}$ slowed germination, it did not stop it. Young et al. (2004) indicated that at the latter temperature, little to no germination was observed; however, their observations were made after $8 \mathrm{~h}$ of incubation. In our study, up to $35 \%$ of spores from isolate WM31 had germinated after $48 \mathrm{~h}$ of incubation and the other two had $10 \%$ germination. This differential behavior may be a sign that WM31, which was originally collected from Nebraska, has better adaptation to higher temperatures than the North Dakota isolates (Uloth et al. 2015). The germ tubes observed after $48 \mathrm{~h}$ of incubation at $30^{\circ} \mathrm{C}$ were shorter than those produced at $21^{\circ} \mathrm{C}$ after $8 \mathrm{~h}$ of incubation; however, that may not necessarily be an impediment for penetration of plant tissues as observed by Jamaux et al. (1995).

Interrupting the incubation period by drying the ascospores for any length of time had a detrimental effect on their germination, a trend that has also been observed on other pathosystems (Arauz and Sutton 1990; Armstrong-Cho et al. 2004; Llorente and Montesinos 2002). The only instance when the percentage of ascospore germination increased significantly after a dry period was observed when said period occurred within $2 \mathrm{~h}$ of suspending the ascospores in water. Since no appreciable increase in the average length of germ tubes was observed after incubating previously dried spores (data not shown), it is very likely the additional germination observed in this treatment was produced by spores that had not initiated the germination process when the dry period started and the spores that did were no longer viable by the end of the drying period.

The inoculation method used to evaluate the role of interrupted wet incubation conditions on ascospore infection efficiency was appropriate, effective, and simulated the natural inoculation process. The use of the Andersen sampler facilitated a uniform distribution of spores on the dishes carrying the flowers and consequently the pathogen was detected on all flowers tested for its presence. Further, the

Table 3. Fitness parameters of logistic regression models that estimate the probability of Sclerotinia disease occurrence from ascosporic infections by S. sclerotiorum on dry bean and canola plants ${ }^{\mathrm{a}}$

\begin{tabular}{|c|c|c|c|c|c|}
\hline \multirow{3}{*}{$\begin{array}{l}\text { Fitness } \\
\text { parameters }\end{array}$} & \multirow{2}{*}{\multicolumn{2}{|c|}{ Dry bean }} & \multicolumn{3}{|c|}{ Canola } \\
\hline & & & \multirow[b]{2}{*}{ Model } & \multirow[b]{2}{*}{ Validation } & \multirow{2}{*}{$\begin{array}{c}\text { Field } \\
\text { validation }\end{array}$} \\
\hline & Model & Validation & & & \\
\hline Sensitivity (\%) & 88 & 83 & 77 & 79 & 77 \\
\hline Specificity (\%) & 86 & 87 & 74 & 70 & 72 \\
\hline Overall accuracy & 87 & 85 & 75 & 73 & 75 \\
\hline
\end{tabular}

a The models for dry bean and canola are $P=1 /\left(1+e^{-\left[-7.39+0.11^{*} \text { moist }\right]}\right)$ and $P=1 /\left(1+e^{-\left[-20.62+(0.046 * \text { moist })+(1.57 * \text { temp })+\left(-0.033 * \text { temp }^{2}\right)\right]}\right)$, respectively. Here, $P$ is probability of disease development, moist is the cumulative number of wet incubation hours in a period of $144 \mathrm{~h}$, temp is incubation temperature, and temp ${ }^{2}$ is the quadratic effect of temperature.

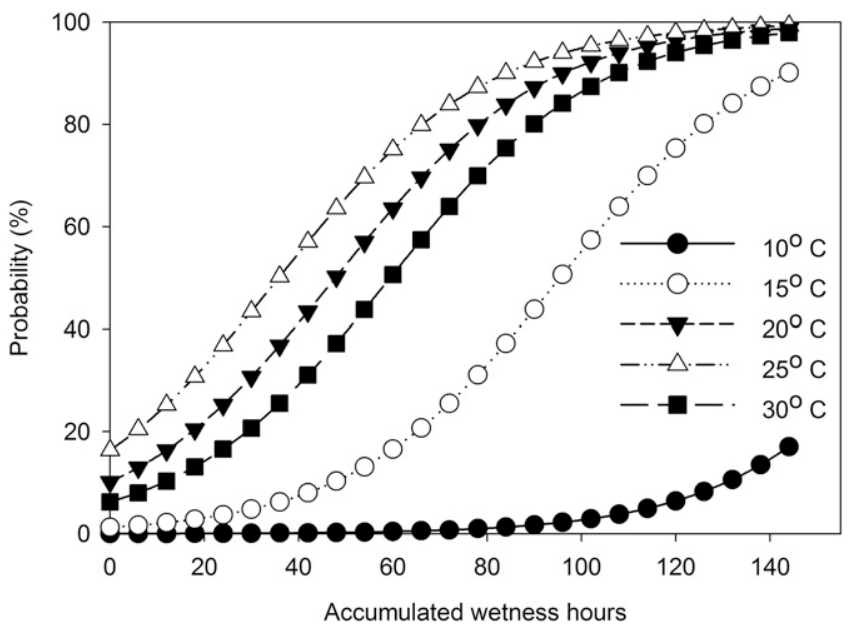

Fig. 3. Influence of leaf wetness duration and incubation temperature during a 6-day period on the probability of Sclerotinia sclerotiorum leaf lesion development on canola cultivar Westar. method allowed incubation conditions to be the sole source of moisture for priming ascospores for germination and did not wound tissues that facilitate penetration into plant tissues as other methods (Botha et al. 2009).

Alternating wet and dry incubation conditions increased the duration of the latent period and reduced the final amount of disease compared with continuous-moisture incubation but did not suppress the disease. According to Harikrishnan and del Río (2006), S. sclerotiorum hyphae is very tolerant to desiccation and could resume growth even when colonized flowers have been dried for a few days. This resiliency was observed in this study too.

The magnitude of the delay in symptom appearance depended on the duration of the wet and dry periods as observed by Phillips (1994) but also on incubation temperature and type of host. The accumulation of $36 \mathrm{~h}$ of leaf wetness at $15^{\circ} \mathrm{C}$ resulted in $6 \%$ chance of disease development; the same number of wet hours would result in a $50 \%$ chance at $25^{\circ} \mathrm{C}$. Increasing the accumulated wetness duration from 36 to $60 \mathrm{~h}$ would raise the chance of disease development to $17 \%$ at $15^{\circ} \mathrm{C}$ and to $75 \%$ at $25^{\circ} \mathrm{C}$. Interestingly, disease developed at $30^{\circ} \mathrm{C}$, a temperature that many researchers consider the upper limit for this pathogen (Abawi and Grogan 1975; Koch et al. 2007, Clarkson et al. 2014; Uloth et al. 2015). Incubating plants for 18 wet hours at $30^{\circ} \mathrm{C}$ resulted in similar disease incidence to incubating plants for $6 \mathrm{~h}$ in $25^{\circ} \mathrm{C}$; however, the lesions were much smaller and did not represent a threat to the plant. However, the fungus could continue developing at faster rates once temperatures cooled down. Disease developed on canola plants faster and required shorter wetness duration than on dry bean plants. In general, when incubated at $20^{\circ} \mathrm{C}$, the canola latent period was 1.4 times shorter and disease
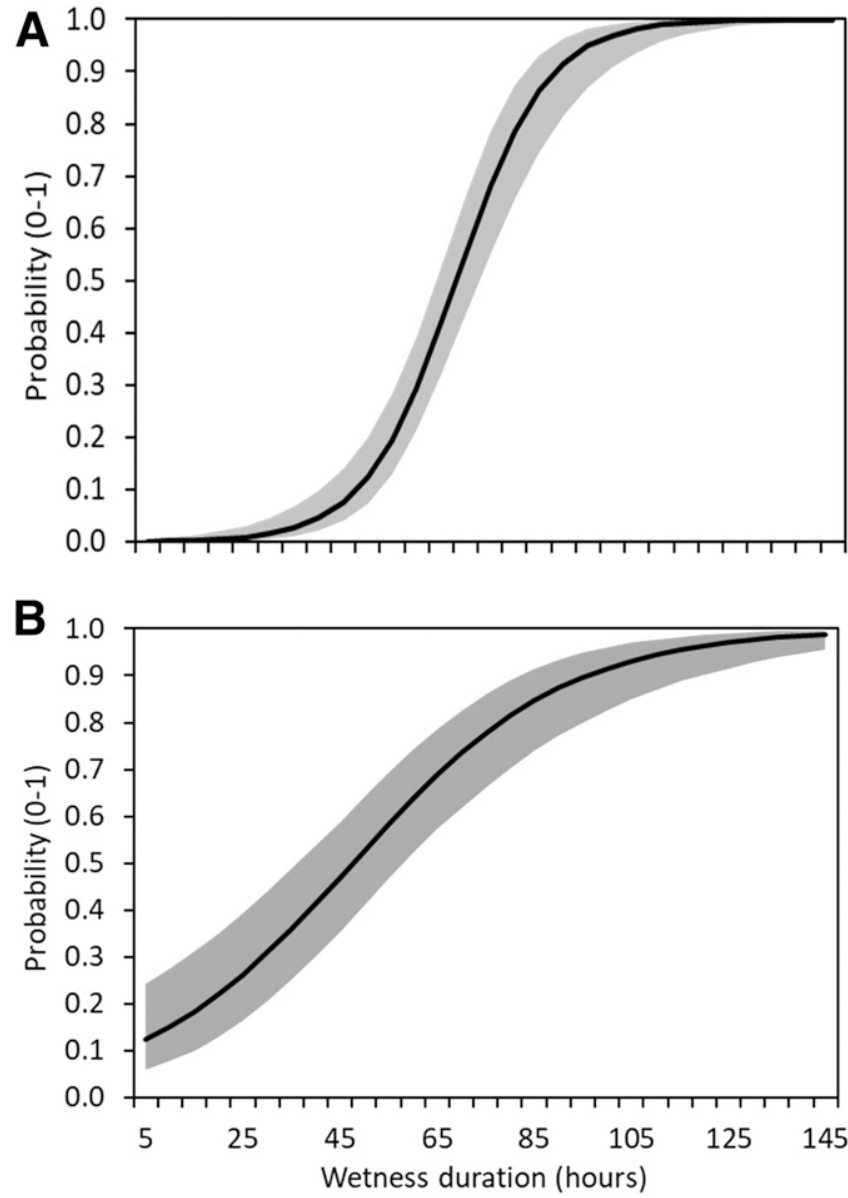

Fig. 4. Predicted probability of Sclerotinia sclerotiorum foliar lesion development on plants of canola cultivar Westar (A) and dry bean cultivar Maverick (B) incubated for $144 \mathrm{~h}$ at $20^{\circ} \mathrm{C}$ under various wetness conditions. Shaded areas represent the $95 \%$ confidence intervals. 
incidence was 1.3 times higher than that of dry bean. While there may be several reasons for this, one of them could be the difference in floral mass; dry bean flowers are on average 2.5 times heavier than canola flowers and thus they offer greater mass and volume of tissues to colonize before hyphae penetrate leaf tissues; at the same time, it is possible that once dried, tissues would take longer to rewet reducing in this way the amount of time available for hyphae to grow. The difference in moisture requirements between these two hosts was reflected in their models.

The importance of leaf wetness in the development of ascosporic infections by $S$. sclerotiorum was pointed out earlier by researchers who studied its role in experiments where wetness conditions were continuous (Abawi and Grogan 1975; Blad et al. 1978; Boland and Hall 1988) and by observations that compared disease intensities in irrigated versus nonirrigated conditions (Weiss et al. 1980). Phillips (1994) studied the impact of discontinuous moisture on the development of S. sclerotiorum; however, his experiments only included a single interruption of the wet incubation conditions although under variable temperature regimes. More recently, Clarkson et al. (2014) evaluated the effect of temperature and relative humidity on disease development but did not evaluate the effect of discontinuous wetness duration. To our knowledge, this is the first study that reports the effect of multiple cycles of wet and dry incubation conditions and uses inoculation of dry ascospores to model disease development.

Repeated cycles of wet and dry conditions not only reduced the ability of ascospores to infect and colonize floral tissues but also allowed for saprophytes to compete for the dead tissues. During the dry bean studies reported here, it was noted that flowers that were not associated with a leaf lesion did not exhibit typical S. sclerotiorum mycelial growth; instead, they were colonized by saprophytes that produced dark brown to black mycelium and/or had a mushy texture, a symptom of tissue degradation. It is very likely that under field conditions, where multiple ascospore showers are possible (Qandah and del Río 2011; Schwartz and Steadman 1978), similar competition would take place limiting the potentially additive effect that said showers would have on the probability of a flower yielding a leaf lesion.

Numerous models have been produced to estimate the risk of Sclerotinia development. Some of them were produced by associating cultural practices and/or weather variables with high intensity epidemics (Clarkson et al. 2014; Harikrishnan and del Río 2008; Workneh and Yang 2000) while others were produced associating the detection of infected plant parts with final disease intensity (Bom and Boland 2000; Turkington and Morrall 1993). While the information generated by these models is useful, their ability to accurately predict disease development is hampered by the fact that none address "disease establishment" in the calculation of the risk of disease development. This issue was addressed in this manuscript.

The models developed for dry bean and canola have high sensitivity and specificity. Sensitivity is defined as the true proportion of cases (e.g., disease present) correctly predicted by the model; specificity refers to the proportion of controls (e.g., disease absent) correctly predicted by the model (Coughlin et al. 1992; Hosmer and Lemeshow 2000). The dry bean model does not include incubation temperature as a predictor; this may be why it also had better sensitivity and specificity than the canola model. In contrast, the canola model does include incubation temperature as a predictor.

To our knowledge, this is the first time that logistic regression models developed for diseases caused by the same pathogen in two crops were compared. While the comparison was limited to a single incubation temperature, the comparison revealed that $70 \mathrm{~h}$ of accumulated wetness was a threshold above which the differences between crops disappeared. This threshold is likely to change, however, as incubation temperatures change. Comparing models is at the heart of the science of epidemiology and if the comparisons are made within the data ranges used to develop the models, they will be appropriate and informative. In this sense, the models for dry bean and canola were developed using experiments that shared common conditions, e.g., $20^{\circ} \mathrm{C}$ as incubation temperature and similar range of accumulated wetness durations obtained through repeated cycles of dry/wet incubation conditions.
The models developed in this study contribute to our understanding of the epidemiology of diseases initiated by S. sclerotiorum ascospores. However, due to its flexibility, the canola model was the only model validated in field conditions. Dew formation was estimated as an indicator of leaf wetness duration. This approach has been used by other researchers in lieu of leaf wetness sensors (Huber and Gillespie 1992; Sentelhas et al. 2008) and is easier to implement by growers. The canola model proved to be accurate in the field and thus could be used as part of a disease-warning system for growers.

\section{Literature Cited}

Abawi, G. S., and Grogan, R. G. 1975. Source of primary inoculum and effects of temperature and moisture on infection of beans by Whetzelinia sclerotiorum. Phytopathology 65:300-309.

Andersen, A. A. 1958. New sampler for the collection, sizing, and enumeration of viable airborne particles. J. Bacteriol. 76:471-484.

Arauz, L. F., and Sutton, T. B. 1990. Effect of interrupted wetness periods on spore germination and apple infection by Botriosphaeria obtusa. Phytopathology 80: 1218-1220.

Armstrong-Cho, C., Gossen, B. D., and Chongo, G. 2004. Impact of continuous and interrupted leaf wetness on infection of chickpea by Ascochyta rabiei. Can. J. Plant Pathol. 26:134-141.

Blad, B. J., Steadman, J. R., and Weiss, A. 1978. Canopy structure and irrigation influence white mold disease and microclimate of dry edible bean. Phytopathology 68:1431-1437.

Boland, G. J., and Hall, R. 1988. Epidemiology of Sclerotinia stem rot of soybean in Ontario. Phytopathology 78:1241-1245.

Bom, M., and Boland, J. G. 2000. Evaluation of disease forecasting variables for Sclerotinia stem rot (Sclerotinia sclerotiorum) of canola. Can. J. Plant Sci. 80: 889-898.

Botha, C., McLaren, N. W., and Swart, W. J. 2009. Evaluation of greenhouse inoculation techniques used to screen for Sclerotinia stem rot resistance in soybeans. S. Afr. J. Plant Soil 26:48-50.

Chapara, V., Chittem, K., and del Río, L. E. 2018. First report of white mold caused by Sclerotinia sclerotiorum on faba beans in North Dakota. Plant Dis. 102: 1669.

Clarkson, J. P., Fawcett, L., Anthony, S. G., and Young, C. 2014. A model for Sclerotinia sclerotiorum infection and disease development in lettuce, based on the effects of temperature, relative humidity and ascospore density. PLoS One 9:e94049.

Coughlin, S. S., Trock, B., Criqui, M. H., Pickle, L. W., Browner, D., and Tefft, M. C. 1992. The logistic modeling of sensitivity, specificity, and predictive value of a diagnostic test. J. Clin. Epidemiol. 45:1-7.

del Río, L. E., Bradley, C. A., Henson, R. A., Endres, G. J., Hanson, B. K., McKay, K., Halvorson, M., Porter, P. M., LeGare, D. G., and Lamey, H. A. 2007. Impact of Sclerotinia stem rot on yield of canola. Plant Dis. 91:191-194.

del Río, L. E., Bradley, C. A., and Johnson, B. L. 2005. First report of white mold caused by Sclerotinia sclerotiorum on Echium (Echium vulgare). Plant Dis. 89:684.

Foley, M. E., Doğramac1, M., West, M., and Underwood, W. R. 2016 Environmental factors for germination of Sclerotinia sclerotiorum sclerotia. J. Plant Pathol. Microbiol. 7:379-383.

Garg, H., Li, H., Sivasithamparam, K., Kuo, J., and Barbetti, M. J. 2010. The infection processes of Sclerotinia sclerotiorum in cotyledon tissue of a resistant and a susceptible genotype of Brassica napus. Ann. Bot. 106:897-908.

Harikrishnan, R., and del Río, L. E. 2006. Influence of temperature, relative humidity, ascospore concentration, and length of drying of colonized dry bean flowers on white mold development. Plant Dis. 90:946-950.

Harikrishnan, R., and del Río, L. E. 2008. A logistic regression model for predicting risk of white mold incidence on dry bean in North Dakota. Plant Dis. 92:42-46.

Hosmer, D. W., and Lemeshow, S. 2000. Applied Logistic Regression, 2nd Ed John Wiley and Sons, Hoboken, NJ.

Hosmer, D. W., Lemeshow, S., and Sturdivant, R. X. 2013. Applied logistic regression, 3rd Ed. John Wiley and Sons, Hoboken, NJ.

Huber, L., and Gillespie, T. J. 1992. Modeling leaf wetness in relation to plant disease epidemiology. Annu. Rev. Phytopathol. 30:553-577.

Jamaux, I., Gelie, B., and Lamarque, C. 1995. Early stages of infection of rapeseed petals and leaves by Sclerotinia sclerotiorum revealed by scanning electron microscopy. Plant Pathol. 44:22-30.

Koch, S., Dunker, S., Kleinhenz, B., Rohrig, M., and Tiedemann, A. 2007. A crop loss-related forecasting model for Sclerotinia stem rot in winter oilseed rape. Phytopathology 97:1186-1194.

Llorente, I., and Montesinos, E. 2002. Effect of relative humidity and interrupted wetness periods on brown spot severity of pear caused by Stemphylium vesicarium. Phytopathology 92:99-104.

Magarey, R. D., Sutton, T. B., and Thayer, C. L. 2005. A simple generic infection model for foliar fungal plant pathogens. Phytopathology 95:92-100.

Phillips, A. J. L. 1994. Influence of fluctuating temperatures and interrupted periods of plant surface wetness on infection of bean leaves by ascospores of Sclerotinia sclerotiorum. Ann. Appl. Biol. 124:413-427. 
Qandah, I., and del Río, L. E. 2011. Temporal dispersal patterns of Sclerotinia sclerotiorum ascospores during canola flowering. Can. J. Plant Pathol. 33:159-167.

Rothmann, L. A., and McLaren, N. W. 2018. Sclerotinia sclerotiorum disease prediction: A review and potential applications in South Africa. S. Afr. J. Sci. 114:1-9.

Schwartz, H. F., and Steadman, J. R. 1978. Factors affecting sclerotium populations of, and apothecium production by, Sclerotinia sclerotiorum. Phytopathology 68:383-388.

Sentelhas, P. C., Marta, A. D., Orlandini, S., Santos, E. A., Gillespie, T. J., and Gleason, M. L. 2008. Suitability of relative humidity as an estimator of leaf wetness duration. Agric. For. Meteorol. 148:392-400.

Steadman, J. R., Marcinkowska, J., and Rutledge, S. 1994. A semi-selective medium for isolation of Sclerotinia sclerotiorum. Can. J. Plant Pathol. 16:68-70.

Turkington, T. K., and Morrall, R. A. A. 1993. Use of petal infestation to forecast Sclerotinia stem rot of canola: the influence of inoculum variation over the flowering period and canopy density. Phytopathology 83:682-689.
Uloth, M. B., You, M. P., Cawthray, G., and Barbetti, M. J. 2015. Temperature adaptation in isolates of Sclerotinia sclerotiorum affects their ability to infect Brassica carinata. Plant Pathol. 64:1140-1148.

Wang, H., Sanchez-Molina, J. A., Li, M., and Rodríguez Díaz, F. 2019. Improving the performance of vegetable leaf wetness duration models in greenhouses using decision tree learning. Water 11:158-177.

Weiss, A., Kerr, E. D., and Steadman, J. R. 1980. Temperature and moisture influences on development of white mold disease (Sclerotinia sclerotiorum) on Great Northern beans. Plant Dis. 64:757-759.

Workneh, F., and Yang, X. B. 2000. Prevalence of Sclerotinia stem rot of soybeans in the north-central United States in relation to tillage, climate, and latitudina positions. Phytopathology 90:1375-1382.

Young, C. S., Clarkson, J. P., Smith, J. A., Watling, M., Phelps, K., and Whipps, J. M. 2004. Environmental conditions influencing Sclerotinia sclerotiorum infection and disease development in lettuce. Plant Pathol. 53:387-397. 